\title{
Gerçek Zamanlı Enerji İzleme ve Tüketici Farkındalığı için LabVIEWTM Programı ile Otomatik Sayaç Okuma
}

\author{
Automatic Meter Reading with LabVIEW ${ }^{\mathrm{TM}}$ Program for Real-Time Energy Monitoring and \\ Consumer Awareness
}

Bilal KARAMAN ${ }^{1}$ iD, Sezai TAȘKIN ${ }^{2}$ (iD), Mert TOKAY ${ }^{3}$

${ }^{1,2}$ Manisa Celal Bayar Üniversitesi, Elektrik Elektronik Mühendisliği Bölümü, 45140, Manisa, Türkiye

${ }^{3}$ Luna Elektrik Elektronik San. Tic. A.Ş. Ar-Ge Merkezi, 35620, İzmir, Türkiye

\section{$\ddot{O} z$}

Akıllı sayaç; kayıp-kaçak oranını azaltma, uzaktan okuma, kontrol etme (açma-kesme) ve faturalandırmanın yanı sıra farklı zaman dilimleri için enerji tüketimi hesaplama ve böylece yük öteleme teşviki gibi özellikleri sayesinde akılllı şebekelerin önemli bir bileşenidir. Bu çalışmada, RS-485 haberleşmesi ve TCP/IP protokolü üzerinden erişim sağlanan akıllı sayaç verileri NI LabVIEWTM programında tasarlanan bir arayüze aktarılmıştır. Böylece, her bir akıllı sayaca ait anlık akım, gerilim, aktifreaktif güç, aktif-reaktif tüketim ve güç katsayısı değerlerinin hem sayısal hem de grafiksel olarak görüntülenmesi, tüketiciye raporlanması ve enerji tarife dilimlerine göre fiyatlandırılması uygulaması gerçekleştirilmiştir. Geliştirilen kullanııı arayüzüne uzaktan erişim imkanı verilerek sayaca ait tüketim verilerinin elektrik dağıtım şirketi ve tüketici tarafindan izlenmesi sağlanmıştır. Çalışmada sunulan yöntem, akıllı sayaç sistemlerine yeni bir ilave maliyet getirmediğinden akıllı şebeke çözümlerine bir katkı sunmaktadır. Ayrıca, tüketicilerin tüketim verilerini sadece fatura dönemlerinde değil sürekli olarak izlemelerine olanak verdiğinden hem enerji tasarrufu farkındalı̆ı hem de puant zaman dilimlerindeki enerji birim fiyatlandırma politikasından dolayı şebeke üzerindeki yükün daha dengeli dağılımına da katkı sağlayabilecek niteliktedir.

Anahtar Kelimeler: Akıllı Şebekeler, Akıllı Elektrik Sayacı, Uzaktan İzleme.

\section{Abstract}

Smart meter; it is an important component of smart grids thanks to its features such as reducing non-technical losses, remote reading, controlling (remote on-off) and billing. In addition, it provides incentives in costumer side such as load shifting for different periods. In this study, smart meter data are transferred to an interface designed in NI LabVIEWTM program by using the RS-485 and TCP/IP protocol. Hence, the parameters including current and voltage, total active and reactive consumption and power factor can be both numerically and graphically monitored over the developed user interface. The method provides a contribution to smart grid solutions without requiring any additional investment for the smart meter systems. Moreover, since it allows consumers to monitor consumption data not only during billing periods, it can also contribute to a more balanced distribution of the load on the grid due to the energy pricing policy in both energy savings and peak time periods.

Keywords: Smart Grids, Smart Meter, Remote Monitoring.

\section{GİRIS}

Akıllı elektrik şebekeleri kavramı ile birlikte, kayıpların azaltılması, tedarik sürekliliğinin iyileştirilmesi, bütünleşik yük yönetimi, manuel süreçlerin asgari seviyeye indirilmesi, kullanıcıların gerçek zamanlı olarak tüketim bilgilerine erişimleri ve piyasaya katılımlarının sağlanması, dinamik tarife uygulamaları, gerçek zamanlı talep takibi, gelişmiş talep tarafı yönetimi gibi mevcut şebeke işleyiş yapısının ötesinde kavramlar oluşmuştur [1]. Akıllı sayaç sistemleri, enerji tüketim noktalarındaki ölçme sistemleri ile merkezi veri sistemi arasında uzaktan iletişim kurarak güvenli bir şekilde veri iletimini gerçekleştiren donanım, yazılım ve haberleşme altyapılarından oluşmaktadır [2]. Akıllı sayaç altyapısı ve veri yönetimi, çift yönlü iletişim ile birlikte enerjinin üretimi, iletimi ve dağıtımı aşamalarında kolaylıklar sağlamaktadır. Puant zaman dilimindeki ortalama yük değerini aşan talebin enerji birim fiyatı teşvikleri ile puant olmayan zamanlara kaydırılması, şebeke yükünün daha dengeli yayılmasına katk1 sağlayabilmektedir. Bunun yanı sıra akıllı şebekelerin en önemli bileşenleri arasında yer alan akıllı sayaç sistemlerinin getirdiği gerçek zamanlı ücretlendirme ve akıllı yük kontrolü gibi uygulamalar sayesinde son kullanıcılar belirlenen enerji tarife dilimleri ile uyumlu oranda tüketimlerini gerçekleştirmekte ve böylece yük ötelemeye yönlenebilmektedirler [3,4]. 
Mevcut durumda ülkemizde ve dünyanın çeşitli ülkelerinde uygulamaları bulunan Otomatik Sayaç Okuma Sistemleri-OSOS (Automatic Meter ReadingAMR) haberleşmenin tek yönlü olduğu, sayaç verilerinin kısa dönem aralıklı (saatlik veya daha az) periyotlarla merkezi sisteme iletildiği sistemlere verilen bir isimlendirmedir. Akıllı sayaç sistemi ise haberleşmenin çift yönlü olduğu, sayaç verilerinin toplanmasının yanı sıra, ölçme sistemlerine uzaktan erişim sağlanarak gelişmiş teknolojik uygulamalara imkan veren sistemlerdir [2]. Akıllı sayaçların uzaktan okuma, açma-kapama gibi sağladığı teknik özellikler özellikle kayıp kaçak oranının yüksek olduğu bölgeler için daha bir önem arz etmektedir [5-7].

Ülkemizde akıllı şebekeler konusunda yapılan çalışmaların temelini OSOS çalışmaları oluşturmaktadır. Türkiye'de faaliyet gösteren 21 Elektrik Dağıtım Şirketinin her biri, yıllık bazda belirli bir tüketim limitinin üzerinde yer alan abonelerini OSOS kapsamına almıştır. Mevcut durumda, bir elektrik sayacının damga süresi 10 y1l olarak kabul edilmektedir ve bu 10 yillık süre sonunda damga süresi dolan sayaçların yenileri ile değiştirilmesi ya da kalibrasyonlarının yapılması şeklinde işleyiş sürdürülmektedir. Ülkemizde yaygın uygulama olarak damga süresi dolan sayaçların akıllı sayaçlar ile değiştirilmesi uygulaması ile akıllı sayaç dönüşümü başlatılmıştır $[8,9]$.

Tüm elektrik dağıtım şirketlerinin temel hedeflerinden birisi de teknik ve teknik olmayan kayıpların azaltılmasıdır. Bu kapsamda akıllı sayaçlar kritik önem arz etmektedir [10]. Nitekim ülkemizde akıllı sayaç pilot uygulamalarında kayıp kaçak kullanımının azaltılmasında bazı bölgelerde \%35'lere varan başarı oranları sağlanmıştır [11].

Literatürde, sayaçların uzaktan okunabilmesi amacıyla çeşitli haberleşme teknolojileri yer almaktadır. Sayaçlarla haberleşme tek yönlü ya da çift yönlü olarak gerçekleştirilebilmektedir. Sayaçların endeks bilgilerinin okunmasının yanı sıra abonelere bildirim gönderme, otomatik faturalandırma ve sayaçların uzaktan açma-kesme uygulamaları da yap1labilmektedir. Son zamanlarda, mevcut enerji dağıtım hatları üzerine daha yüksek frekanstaki bilginin bindirilmesiyle sağlanan Power Line Communication (PLC) haberleşmesi konusunda çalışmalar sürdürülmektedir [12]. Bu haberleşme yönteminde mevcut sisteme ilave kablolu veya kablosuz herhangi bir donanım gereksinimi yoktur. Haberleşme mevcut enerji hattı üzerinden gerçekleştirilmektedir. Bu şekilde tek bir trafo altındaki yüzlerce sayacın endeks bilgilerinin okunması ve cihazların yönetilmesi sağlanabilmektedir. Radio Frequency (RF) haberleşmesi yönteminde ise yüksek frekans dalga bandında akıllı sayaçlar ile veri toplayıcı üniteler arasında iletişim kurulmaktadır [13]. Sinyal gücüne ve kullandıkları frekans bandına bağlı olarak Bluetooth, Wi-Fi, Zigbee ve LoRa gibi haberleşme protokolleri de RF teknolojisi altında sinıflandırılabilir [14]. Şehirleşmenin yoğun olduğu bölgelerdeki akıllı sayaç uygulamaları için RF haberleşme teknolojisi bir çözüm olarak değerlendirilmektedir. M-Bus standardı (EN 13757-3) farklı üreticilerin 1sı, gaz, su ve elektrik sayaçlarını uzaktan okumak için kullanılan kablolu çözümdür. Kablosuz M-Bus standardı (EN 13757-4) ise RF teknolojisi kullanarak sayaçların verilerinin okunması için kullanılan bir çözümdür [15]. Public Switched Telephone Network (PSTN) haberleşme teknolojisinde ise temel katman olarak telekomünikasyon altyapısı kullanılmaktadır. Ancak, PLC yöntemindeki elektriksel gürültü gibi etkenler söz konusu olmamasına rağmen işletme maliyetlerinin yüksek olması bu sistemin bir dezavantajıdır. GSM/GPRS teknolojisi ise ülkemizde sayaçların uzaktan okunmasında yaygın olarak kullanılan teknolojilerin başında gelmektedir. İlk yatırım maliyetlerinin düşük olmasına karşın işletme maliyetleri yüksektir [2]. GSM/GPRS teknolojisi, özellikle dağınık bir şekilde konumlandırılmış ve belirli tüketim değerini aşan abonelerin sayaçlarının uzaktan okunmasında tercih edilmektedir.

Elektrik perakende şirketlerinin elektrik sayaçlarının okunması ve müşterilerin faturalandırılması süreçlerinde yaşadığı bazı sıkıntılar arasında; abonelerden borçlarını tahsil edememe, bazı abonelere ulaşılamaması nedeniyle sayaçların okunamaması ve uzak noktalardaki abonelere ulaşım maliyetleri yer almaktadır.

Mevcut işleyişte ay sonu faturalandırma şeklinde bir yöntem kullanılmakta ve bu faturalandırma neticesinde borç durumuna göre abonelerin enerjisi kesilerek borçlarını tahsil etme yoluna gidilmektedir. Akıllı elektrik sayaçlarının kullanılmaya başlanması ile birlikte dağıtım şirketleri sayaca yapılan ve/veya yasal olmayan tüm müdahaleleri tespit etme, uzaktan açmakapama işlemlerini yönetme ve sayaçların endeks bilgilerine anlık olarak erişebilme gibi imkanlara kavuşmuşlardır.

$\mathrm{Bu}$ çalışmada, tüketicilerin enerji tarife dilimlerine uygun olarak tüketim planlamalarını yapabilmeleri, toplam tüketim ve güncel fatura bilgilerini izleyebilmeleri amaciyla NI LabVIEW ${ }^{T M}$ grafiksel programında akıllı sayaç verilerine erişebilen bir kullanıcı arayüzü geliştirilmiştir. Geliştirilen uygulama ile akıllı sayaca RS-485 portu üzerinden doğrudan erişim sağlanarak ya da sayacın RS-485 portuna bağlanan bir Wi-Fi modülü ile birlikte TCP/IP haberleşmesi üzerinden uzaktan erişim sağlanarak sayacın seri numarası, aktif - reaktif endeks bilgileri, aktif - reaktif güç bilgileri, akım, gerilim ve güç katsayısı bilgileri okunarak tüketiciye ve dağıtım şirketine raporlanmaktadır. 


\section{MATERYAL VE YÖNTEM}

Bu çalışmada deneysel araç olarak RS-485 haberleşme portuna sahip LUNA marka LSM10 modeli 1 fazl aktif-reaktif akıllı elektronik elektrik sayac1 kullanılmıştır [16]. Akıllı sayaçlar düşük güç tüketimli bir mikrokontrolöre (MCU) sahip olup elektriksel ölçümler için gerekli yeteneklere sahip olarak donatılmışlardır. Akıllı sayacın temel seviye katmanında, gerilim ve akım ölçüm katları yer almaktadır. Nötr akımını ölçmek için de ayrı bir akım ölçüm katı kullanıldığından akım ölçümü iki ayrı kısımdan oluşmaktadır. Bu ölçüm katlarından alınan veriler enerji ölçüm entegresine girilerek UART, I2C, SPI gibi haberleşme protokollerinden birisi ile MCU'ya iletilir $[17,18]$. Aynı zamanda, sayaç üzerindeki röle ile uzaktan açma-kesme işlemleri yapılabilmektedir. Şekil 1 'de bir akıllı sayacın genel mimarisi gösterilmiştir.

Uygulama materyali olarak kullanılan akıllı sayaçta akım, gerilim ve güç ölçümleri $4096 \mathrm{~S} / \mathrm{s}$ (Sample/second) örnekleme alınarak gerçekleştirilmektedir. Akıllı sayaçta sırasıyla gerilim ve akım ölçümü Eşitlik (1) ve (2) kullanılarak hesaplanmaktadır [19].

$$
\begin{gathered}
V_{R M S}=K_{v} \sqrt{\frac{\sum_{n=1}^{N} v^{2}(n)}{N}} \\
I_{R M S}=K_{i} \sqrt{\frac{\sum_{n=1}^{N} i^{2}(n)}{N}}
\end{gathered}
$$

Burada;

$V_{R M S} \quad$ : Gerilim etkin değeri

$I_{R M S} \quad$ : Yük akımı etkin değeri

$K_{v} \quad$ : Gerilim kazanç çarpanı

$K_{i} \quad$ : Akım kazanç çarpanı

$N \quad: 1$ saniyede örneklenen sinyal sayısı

$v(n) \quad: 1$ saniyedeki n. gerilim değeri

i(n) : 1 saniyedeki n. akım değeri

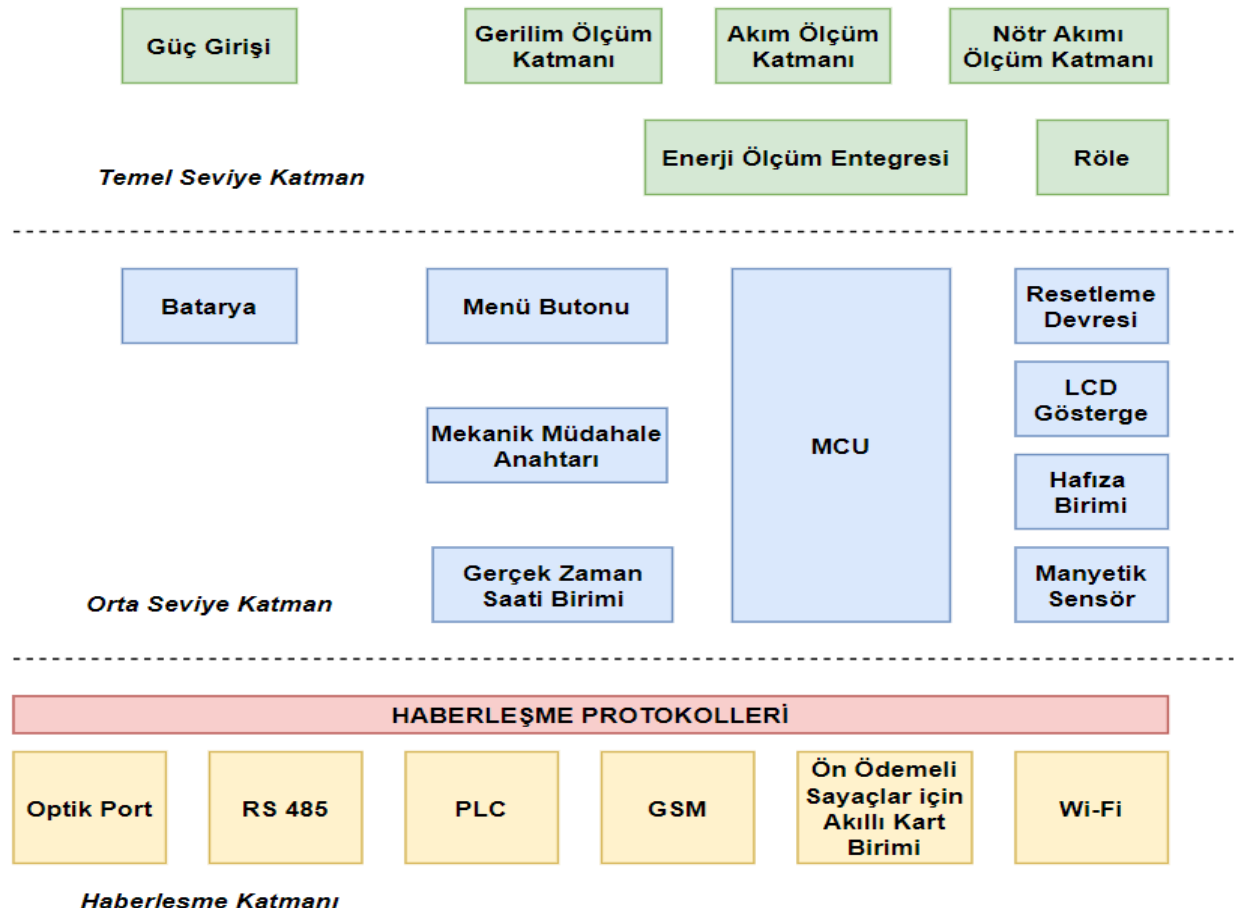

Şekil 1. Akıllı sayacın genel mimarisi

Aktif ve reaktif güçler ise, ölçülen akım ve gerilim örneklemelerinden yola çıkılarak Eşitlik (3) ve (4) kullanılarak hesaplanmaktadır [19].

$$
\begin{aligned}
& P_{A C T}=K_{p} \sqrt{\frac{\sum_{n=1}^{N} v(n) \cdot i(n)}{N}} \\
& P_{R E A C T}=K_{p} \sqrt{\frac{\sum_{n=1}^{N} v_{90}(n) \cdot i(n)}{N}}
\end{aligned}
$$

Burada;

$P_{A C T} \quad$ : Aktif güç değeri

$P_{\text {REACT }} \quad$ : Reaktif güç değeri

$K_{p} \quad$ : Güç için kazanç çarpanı

$N \quad: 1$ saniyede örneklenen sinyal sayısı

$v_{(90)}:$ Örnekleme anındaki gerilim ve akım arasındaki 90 derece faz farkı. 
Akıllı sayacın orta seviye katmanında, MCU'da hesaplanan değerler LCD ekranda gösterilir ve sayacın hafızasında saklanır. Manyetik sensör ve mekanik müdahale anahtarı sayesinde sayaca yapılan müdahalelerin tespit edilip raporlanması sağlanır [20]. Akıllı sayaçların haberleşme katmanlarında ise çeşitli haberleşme protokolleri yer alabilmektedir. Müşteri tarafından talep edilen haberleşme protokollerinden bir veya bir kaçı sayaç tarafindan desteklenmektedir.

Bu çalışmada ilk olarak, akıllı sayacın RS-485 portundan haberleşmenin sağlanabilmesi için RS-485 Okuyucu kullanılmıştır. RS-485 Okuyucu, 300-230400 BaudRate aralığındaki hızları desteklemektedir. Ayrıca ikinci bir opsiyon olarak ise TCP/IP haberleşme protokolü ile akıllı sayaç verilerinin uzaktan okunabilmesi için sayacın RS-485 portuna Espressif firmasının ESP8266 modelindeki Wi-Fi modülü bağlanmıştır. Bu yapıda, kullanıcılar geliştirilen arayüz ve raporlama sistemine kullanıcı adı ve şifre bilgileri ile giriş yaparak, sayaca erişim metodunu RS-485 veya TCP/IP olarak seçebilmekte ve bu sayede sayaç endekslerini ve tüketim bilgilerini anlık olarak izleyebilmektedirler.

2.1. RS-485 Portu ile Akıllı Sayaçların Haberleşmesi RS-485, seri iletişim sistemlerinde kullanılan haberleşme standardıdır. Akıllı sayaç verilerinin haberleşmeyi sağlayan modemler tarafından ya da elektronik cihazlar vasıtasıyla okunabilmesi için IEC 62056-6-1:2017 standardına göre OBIS (OBject Identification System) kodlamasına uyulması gerekmektedir. OBIS kodları ile akıllı sayaçların üretici firmalarına ya da modellerine bağlı olmaksızın, her bir verinin standart olarak belirlenmiş özel kodlar ile sorgulanması ve okunması sağlanmaktadır. Bu çalışmada akıllı sayaçtan okunan verilere ait OBIS kodları Tablo 1'de verilmiştir.
Tablo 1. Kullanılan Akıllı Sayaç OBIS Kodları

\begin{tabular}{|l|l|l|}
\hline $\begin{array}{l}\text { OBİS } \\
\text { Kodu }\end{array}$ & Açılama & $\begin{array}{l}\text { Veri } \\
\text { Formatı }\end{array}$ \\
\hline 0.0 .0 & Sayaç seri numarası & \\
\hline 1.8 .0 & Kümülatif aktif enerji & $(123456.789)$ \\
\hline 1.8 .1 & Gündüz tarifesi toplam enerji & $(123456.789)$ \\
\hline 1.8 .2 & Puant tarifesi toplam enerji & $(123456.789)$ \\
\hline 1.8 .3 & Gece tarifesi toplam enerji & $(123456.789)$ \\
\hline 5.8 .0 & Reaktif endüktif & $(123456.789)$ \\
\hline 8.8 .0 & Reaktif kapasitif & $(123456.789)$ \\
\hline 33.7 .0 & Güç katsayıs1 & $(1.234)$ \\
\hline 32.7 .0 & Gerilim değeri & $(123.45)$ \\
\hline 31.7 .0 & Akım değeri & $(1.234)$ \\
\hline
\end{tabular}

Mevcut OSOS uygulamalarında GSM haberleşme teknolojisi yaygın olarak kullanılmaktadır. Sayaç verilerinin RS-485 haberleşme portu üzerinden GSM modemlere aktarılması sayesinde merkezi veri sistemleriyle iletişim kurulmaktadır. Bu sayede enerji yönetimi, enerji kayıplarının ve kaçak kullanımın tespiti, otomatik arıza tespiti ve otomatik faturalandırma gibi avantajlar elde edilmektedir. OSOS sistem mimarisi Şekil 2'de verilmiştir. Bu yapıda, bir GSM modem üzerinden maksimum 64 sayaca kadar okuma işlemi gerçekleştirilebilmektedir. Sayaçlardaki RS-485 haberleşmesi uygulamalarına bir diğer örnek ise PLC haberleşme teknolojisidir. $\mathrm{Bu}$ sistemde apartmanlar, iş merkezleri, alışveriş merkezleri gibi alanlarda PLC haberleşmesi uygulamaları için her bir sayacın kendi üzerinde PLC modülü bulundurmasına ihtiyaç duyulmamaktadır. $\mathrm{Bu}$ tür sayaçlar, RS-485 portu ile tek bir PLC modeme seri bağlanarak haberleşmektedir [10].

NI LabVIEW ${ }^{\mathrm{TM}}$ ortamında geliştirilen program ile akıllı sayacın RS-485 portu üzerinden haberleşme yöntemi Şekil 3 'te gösterilmiştir.
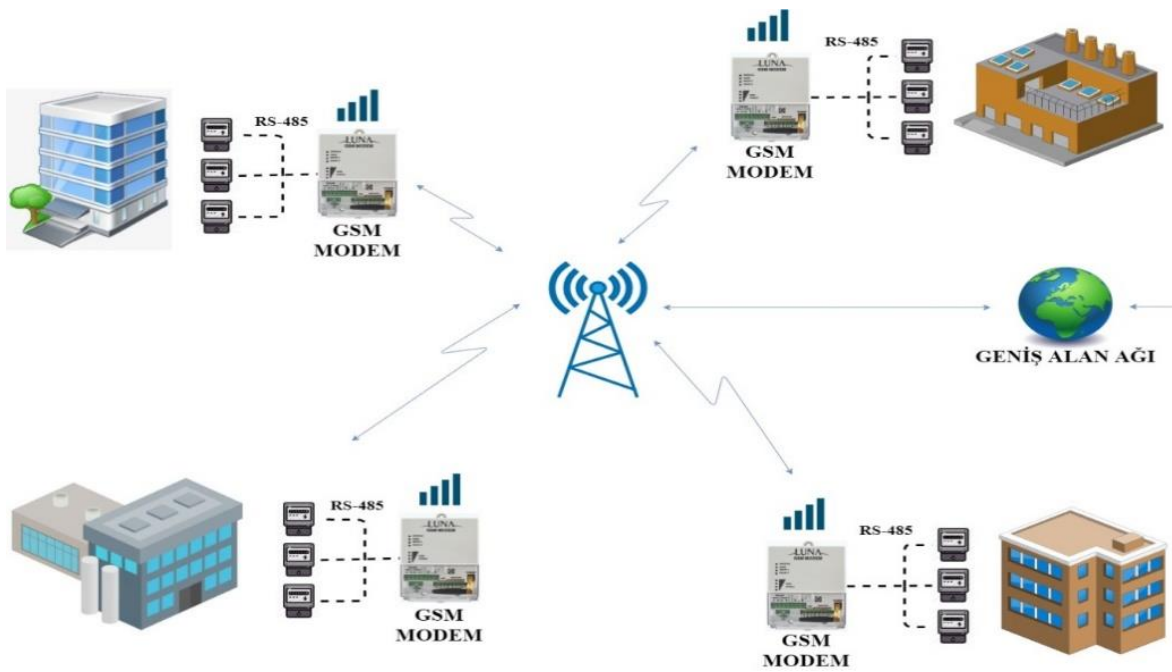

Şekil 2. OSOS sistem mimarisi 


\section{LabVIEW Arayüz Programı}

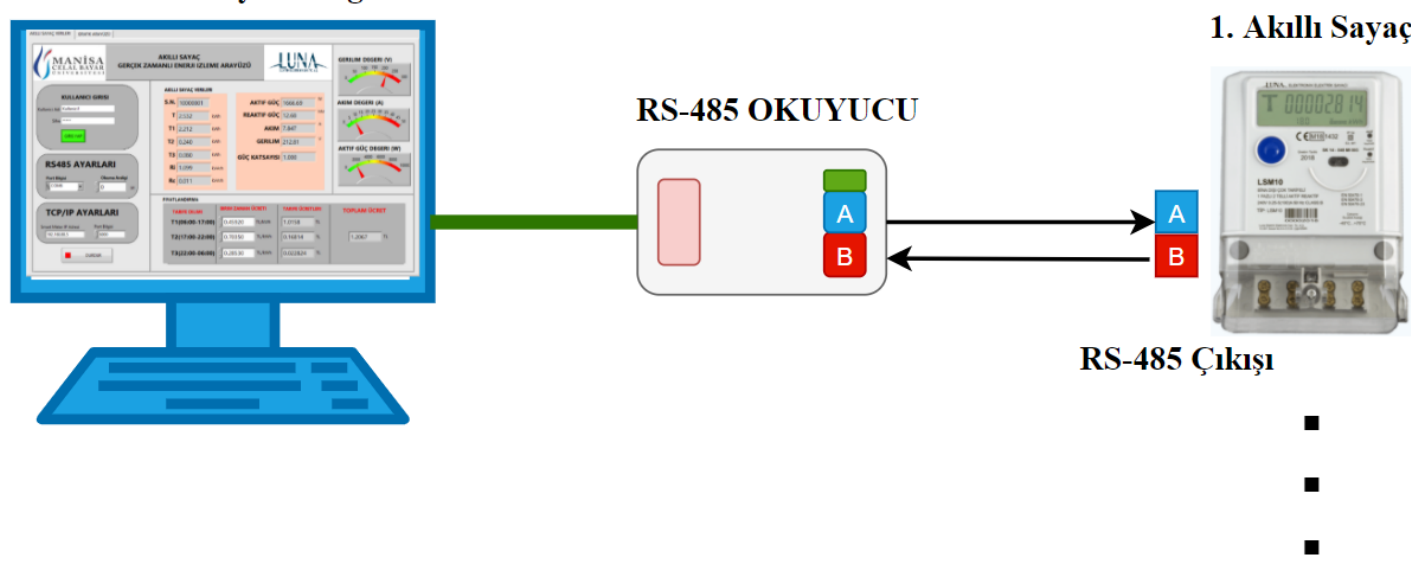

n. Akıllı Sayaç

Şekil 3. RS-485 portu üzerinden akıllı sayaç ve NI LabVIEW ${ }^{\mathrm{TM}}$ programı haberleşmesi

\subsection{TCP/IP Protokolü ile Sayaç Verilerinin}

\section{Görselleștirilmesi}

NI LabVIEW ${ }^{\mathrm{TM}}$ ortamında geliştirilen program ile akıllı sayaca uzaktan erişimin sağlanabilmesi için akıllı sayaca bir Wi-Fi modülü ilave edilmiştir. Sayacın RS485 portuna, RS485-TTL UART Converter vasitasiyla Wi-Fi modülü bağlanmıştır. $\mathrm{Bu}$ işlem için Espressif firmasının ESP8266 modelindeki Wi-Fi ürünü tercih edilmiştir. ESP8266 Wi-Fi modülü, 32-bit düşük güç tüketimli işlemciye ve TCP/IP stack desteğine sahiptir. $2.4 \mathrm{GHz}$ frekans bandında çalışan bu modül, IEEE $802.11 \mathrm{~b} / \mathrm{g} / \mathrm{n}$ protokollerini desteklemektedir [21].

$\mathrm{Bu}$ modül sayesinde, sayaç bir sunucu görevi görmektedir. Bu modülün bağlandığı Wi-Fi modemde port yönlendirilmesi yapılarak sayacın uzaktan erişiminin açık hale getirilmesi sağlanmıştır. Wi-Fi modülünün konfigürasyonlarının yapılabilmesi için izlenen akış diyagramı Şekil 4'te verilmiştir.

Geliştirilen program ile birlikte bir istemci olarak sayaca uzaktan erişim sağlanarak, sayaç verileri anlık olarak takip edilebilmektedir. Şekil 5'te sayacın uzaktan okunmasına ait haberleşme mimarisi verilmiştir.

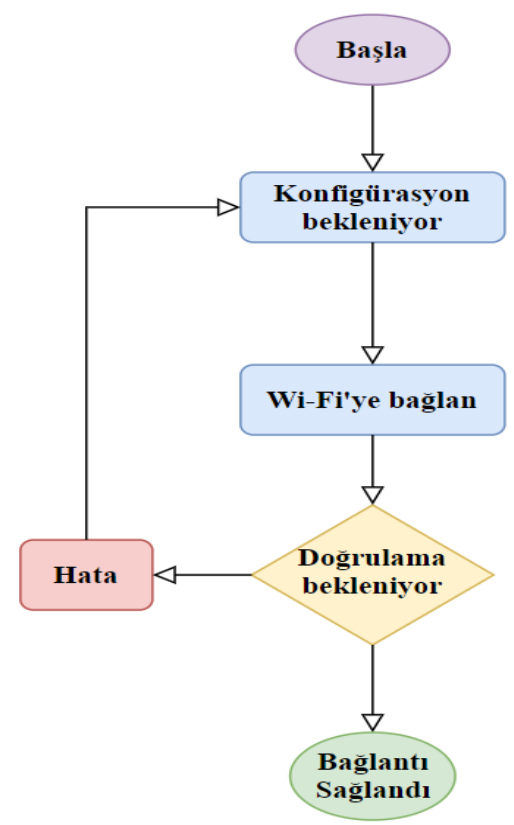

Şekil 4. Akıllı Sayaç Wi-Fi modülü konfigürasyonu akış diyagramı

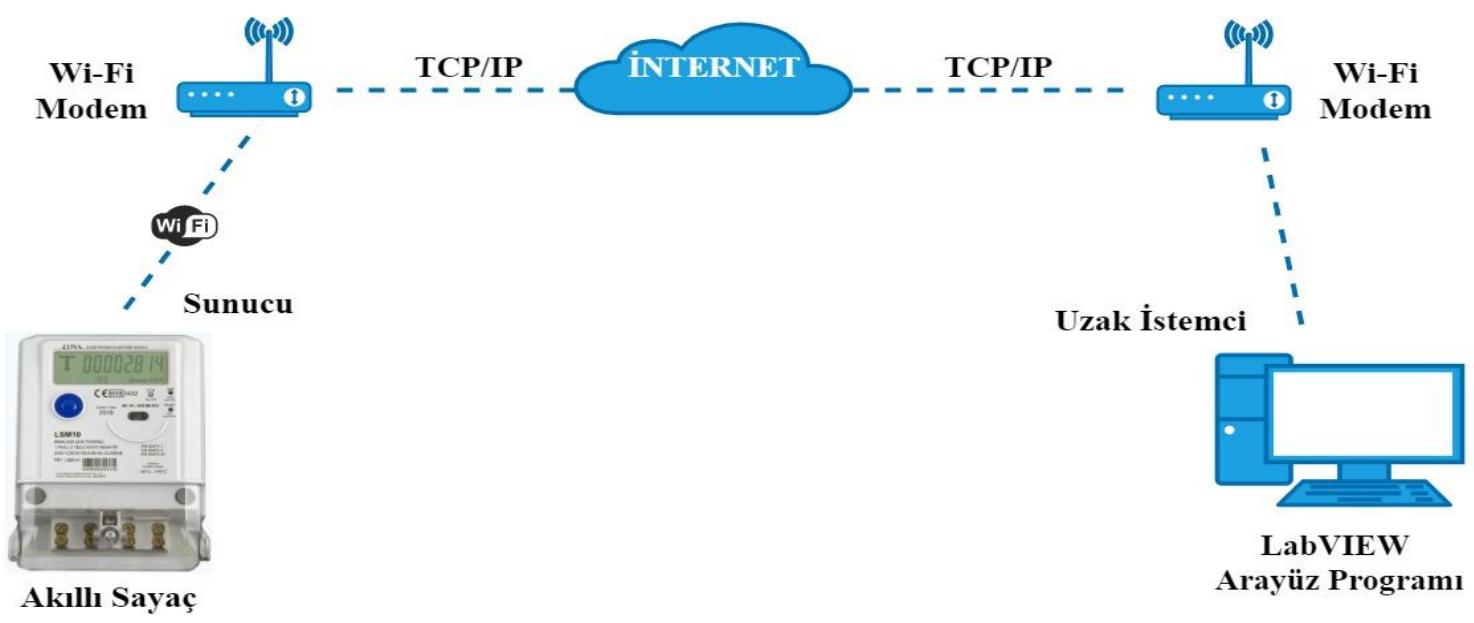

Şekil 5. TCP/IP Protokolü ile sayacın uzaktan okunması 


\section{BULGULAR VE TARTIŞMA}

Akıllı sayaçlar 15, 30 ve 60 dakikalık periyodlar ile uzaktan okunabilmektedir. Bu çalışmada, akıllı sayaç verilerine erişim TCP/IP haberleşme protokolü üzerinden $5 \mathrm{~S} / \mathrm{s}$ olarak seçilmiştir. Fakat, izleme ara yüzünde örnekleme hızı kullanıcı tarafindan değiştirilebilmektedir. Şekil 6'da geliştirilen kullanıcı arayüzü, Şekil 7'de ise sayaç verilerinin grafiksel olarak gösterildiği arayüz ekranı verilmiştir.
Sayaçtan okunan veriler sırasıyla; sayaç seri numarası, toplam tüketim, T1, T2, T3 zaman dilimlerindeki enerji tüketimleri, reaktif-endüktif ve reaktif-kapasitif güç değerleri, güç katsayısı, akım, gerilim, aktif tüketim ile reaktif anlık güç değerlerinden oluşmaktadır. Ayrıca, sayaç verilerinin Excel formatında zamana göre kaydedilmesine ait veri ekranı Tablo 2'de verilmiştir.

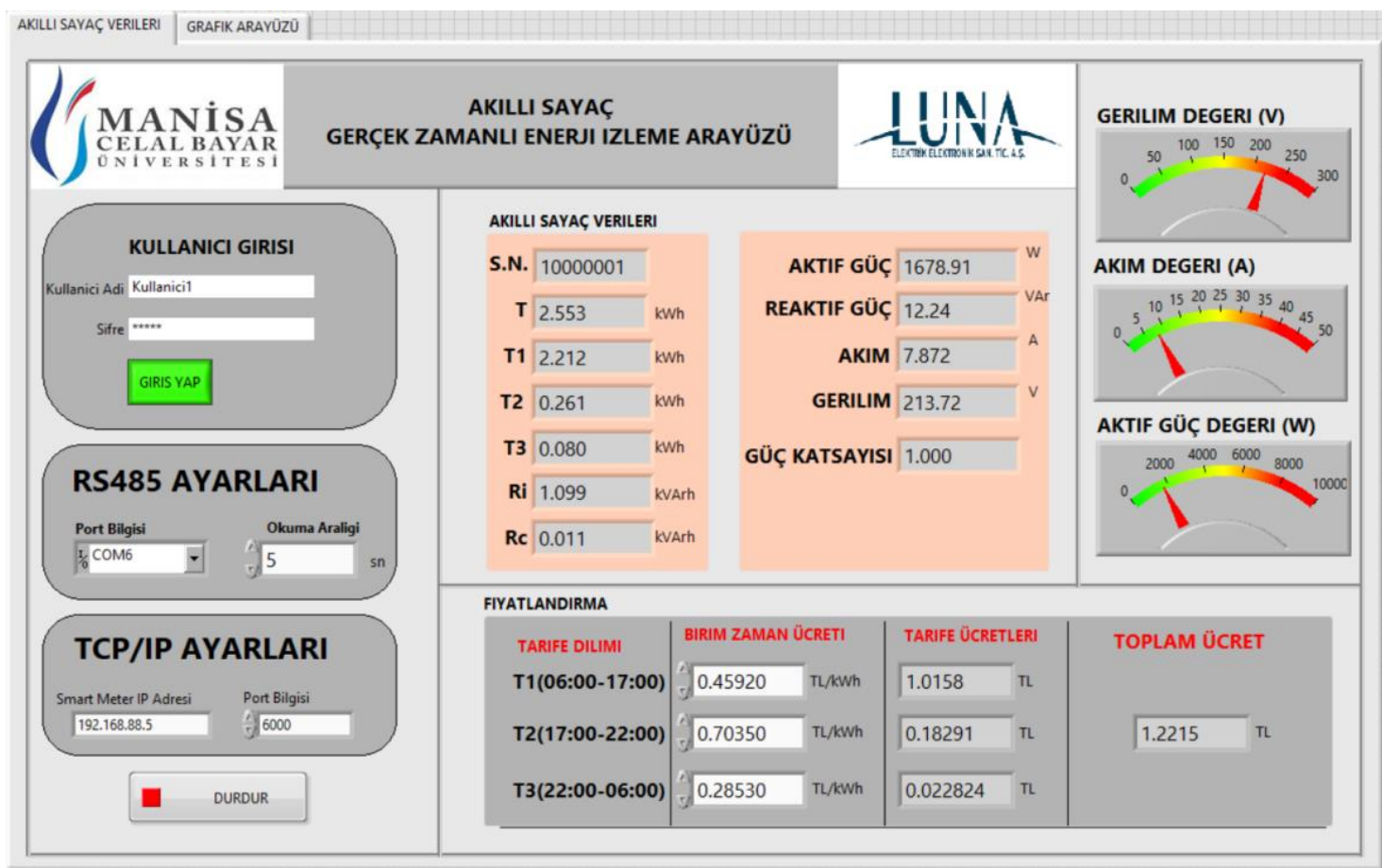

Şekil 6. TCP/IP haberleşmesi ile sayaca uzaktan erişim arayüzü

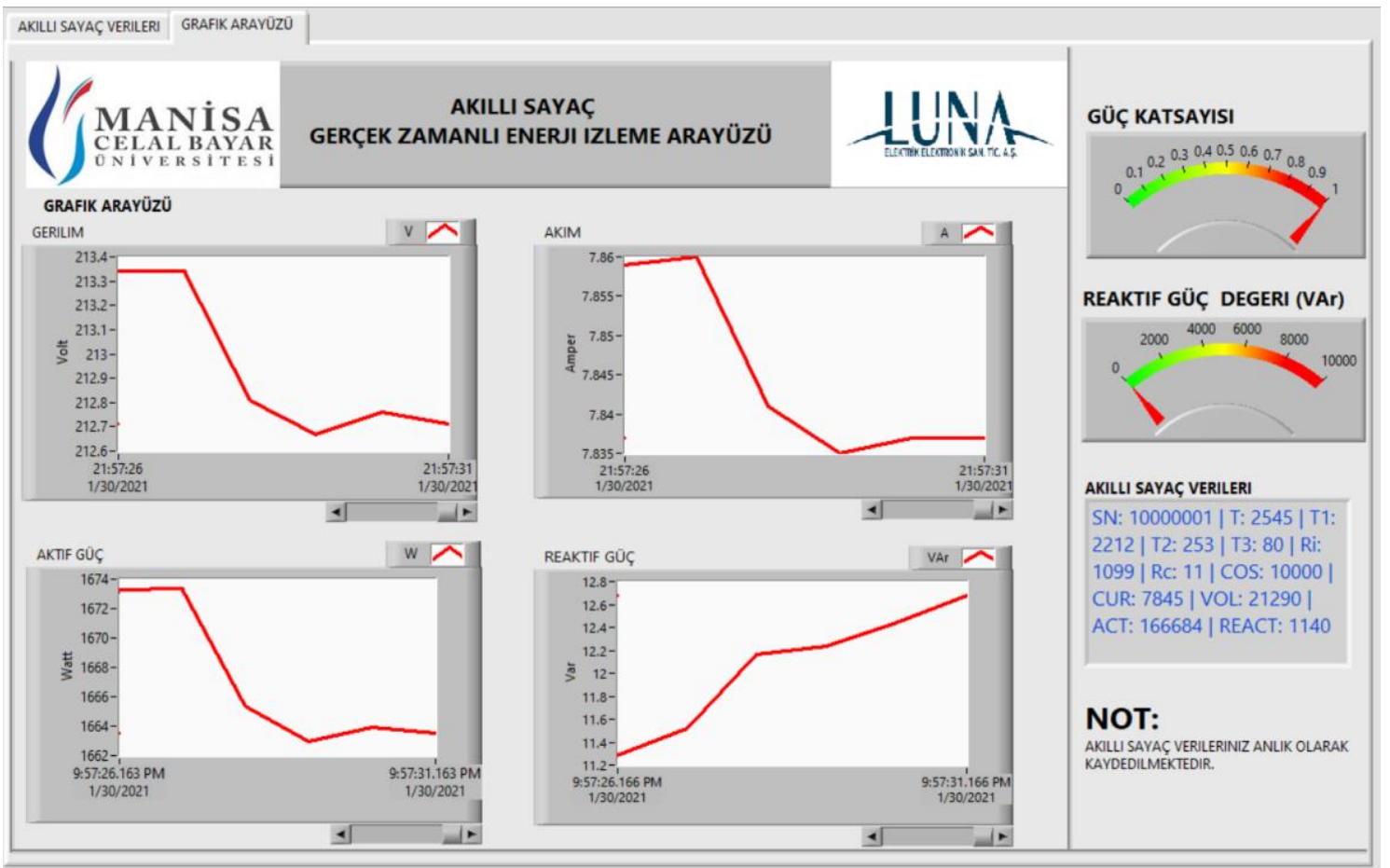

Şekil 7. Akıllı sayaç verilerinin grafiksel olarak izlenmesi 
Tablo 2. Akıllı sayaç verilerinin Excel formatında anlık olarak raporlanması

\begin{tabular}{|c|c|c|c|c|c|c|c|c|c|c|c|c|c|c|c|c|}
\hline Tarih ve Saat & Sayaç Seri No & $T(k W h)$ & $\mathrm{T} 1$ (kWh) & $\mathrm{T} 2(\mathrm{kWh})$ & $\mathrm{T} 3(\mathrm{kWh})$ & Ri (kVah) & Rc (kVah) & Güç Katsa) & $\operatorname{KIM}(A)$ & GERILIM (V) & AKTIF GÜÇ (W) & REAKTIF GÜÇ (VA) & T1 ÜCRET & T2 ÜCRET & 3 ÜCRET & TOPLAM ÜCRET (TL) \\
\hline 1/30/2021 21:56 & 10000001 & 2.524 & 2.212 & 0.232 & 0.08 & 1.099 & 0.011 & 1 & 7.465 & 214.61 & 1507.94 & 11 & 1.016 & 0.163 & 0.023 & 1.201 \\
\hline 1/30/2021 21:56 & 10000001 & 2.524 & 2.212 & 0.232 & 0.08 & 1.099 & 0.011 & 1 & 7.465 & 214.61 & 1507.94 & 11 & 1.016 & 0.163 & 0.023 & 1.201 \\
\hline 1/30/2021 21:56 & 10000001 & 2.524 & 2.212 & 0.232 & 0.08 & 1.099 & 0.011 & 1 & 7.465 & 214.61 & 1507.94 & 11 & 1.016 & 0.163 & 0.023 & 1.201 \\
\hline 1/30/2021 21:56 & 10000001 & 2.524 & 2.212 & 0.232 & 0.08 & 1.099 & 0.011 & 1 & 7.465 & 214.61 & 1507.94 & 11 & 1.016 & 0.163 & 0.023 & 1.201 \\
\hline 1/30/2021 21:56 & 10000001 & 2.524 & 2.212 & 0.232 & 0.08 & 1.099 & 0.011 & 1 & 7.465 & 214.61 & 1507.94 & 11 & 1.016 & 0.163 & 0.023 & 1.201 \\
\hline 1/30/2021 21:56 & 10000001 & 2.524 & 2.212 & 0.232 & 0.08 & 1.099 & 0.011 & 1 & 7.465 & 214.61 & 1507.94 & 11 & 1.016 & 0.163 & 0.023 & 1.201 \\
\hline 1/30/2021 21:56 & 10000001 & 2.524 & 2.212 & 0.232 & 0.08 & 1.099 & 0.011 & 1 & 0.004 & 228.05 & 0 & 0.16 & 1.016 & 0.163 & 0.023 & 1.201 \\
\hline 1/30/2021 21:56 & 10000001 & 2.529 & 2.212 & 0.237 & 0.08 & 1.099 & 0.011 & 1 & 7.859 & 212.93 & 1669.99 & 12.32 & 1.016 & 0.163 & 0.023 & 1.202 \\
\hline 1/30/2021 21:56 & 10000001 & 2.529 & 2.212 & 0.237 & 0.08 & 1.099 & 0.011 & 1 & 7.854 & 212.9 & 1668.73 & 12.36 & 1.016 & 0.167 & 0.023 & 1.202 \\
\hline 1/30/2021 21:56 & 10000001 & 2.53 & 2.212 & 0.238 & 0.08 & 1.099 & 0.011 & 1 & 7.852 & 212.88 & 1668.13 & 12.36 & 1.016 & 0.167 & 0.023 & 1.205 \\
\hline 1/30/2021 21:57 & 10000001 & 2.531 & 2.212 & 0.239 & 0.08 & 1.099 & 0.011 & 1 & 7.855 & 213 & 1669.87 & 11.92 & 1.016 & 0.167 & 0.023 & 1.206 \\
\hline 1/30/2021 21:57 & 10000001 & 2.531 & 2.212 & 0.239 & 0.08 & 1.099 & 0.011 & 1 & 7.854 & 212.97 & 1669.28 & 12.32 & 1.016 & 0.168 & 0.023 & 1.206 \\
\hline 1/30/2021 21:57 & 10000001 & 2.532 & 2.212 & 0.24 & 0.08 & 1.099 & 0.011 & 1 & 7.847 & 212.81 & 1666.69 & 12.68 & 1.016 & 0.168 & 0.023 & 1.207 \\
\hline 1/30/2021 21:57 & 10000001 & 2.532 & 2.212 & 0.24 & 0.08 & 1.099 & 0.011 & 1 & 7.845 & 212.76 & 1665.69 & 12.68 & 1.016 & 0.169 & 0.023 & 1.207 \\
\hline 1/30/2021 21:57 & 10000001 & 2.533 & 2.212 & 0.241 & 0.08 & 1.099 & 0.011 & 1 & 7.844 & 212.78 & 1665.73 & 11.84 & 1.016 & 0.169 & 0.023 & 1.207 \\
\hline 1/30/2021 21:57 & 10000001 & 2.533 & 2.212 & 0.241 & 0.08 & 1.099 & 0.011 & 1 & 7.847 & 212.88 & 1667.08 & 11.64 & 1.016 & 0.17 & 0.023 & 1.207 \\
\hline 1/30/2021 21:57 & 10000001 & 2.534 & 2.212 & 0.242 & 0.08 & 1.099 & 0.011 & 1 & 7.856 & 213.09 & 1670.73 & 12.08 & 1.016 & 0.17 & 0.023 & 1.208 \\
\hline 1/30/2021 21:57 & 10000001 & 2.534 & 2.212 & 0.242 & 0.08 & 1.099 & 0.011 & 1 & 7.853 & 213.09 & 1670.02 & 12.08 & 1.016 & 0.17 & 0.023 & 1.208 \\
\hline 1/30/2021 21:57 & 10000001 & 2.535 & 2.212 & 0.243 & 0.08 & 1.099 & 0.011 & 1 & 7.85 & 212.97 & 1668.47 & 11.92 & 1.016 & 0.17 & 0.023 & 1.209 \\
\hline 1/30/2021 21:57 & 10000001 & 2.535 & 2.212 & 0.243 & 0.08 & 1.099 & 0.011 & 1 & 7.847 & 212.95 & 1667.72 & 12.08 & 1.016 & 0.171 & 0.023 & 1.209 \\
\hline
\end{tabular}

\section{SONUC VE DEĞERLENDİRMELER}

Bu çalıșmada; tüketicilerin akıllı sayaç verilerini anlık olarak izleyebilmelerine imkan tanıyan bir uygulama gerçekleştirilmiştir. Akıllı sayaç sistemlerinde yaygın olarak kullanılan RS-485 haberleşmesine sahip bir elektrik sayacına erişim sağlanarak elektriksel parametreler okunmuş ve NI LabVIEW ${ }^{\mathrm{TM}}$ programı ile geliştirilen kullanıcı arayüzü üzerinden izleme ve tüketim verilerinin raporlanması sağlanmıştır.

Bunun yanı sıra, akıllı sayacın RS-485 haberleşme portuna bir Wi-Fi modülü eklenerek, sayaç verilerine mobil cihazlar üzerinden erişilebilmesi için gerekli donanımsal altyapı oluşturulmuştur. Böylece, tüketicilerin tüketim verilerini kolaylıkla izlemesi ve analiz etmesi mümkün hale gelecektir. Verilerin enerji tarife dilimlerine göre fiyatlandırılması, tüketicilerin daha bilinçli bir tüketim davranışına yönlendirilmesine ve aynı zamanda farklı zaman dilimleri için tanımlanan enerji birim fiyatı teşviklerinden dolayı dağıtım şebekesindeki yük talebinin daha dengeli bir dağılım göstermesine katkı sağlayabilecektir. Ayrıca, bu çalışmada sunulan yöntem, Wi-Fi haberleşmeli yeni nesil akıllı sayaç uygulamalarının geliştirilmesi için de bir uygulama örneği oluşturmaktadır.

\section{KAYNAKLAR}

[1] Türkiye Akıllı Şebekeler 2023 Vizyon ve Strateji Belirleme Projesi, ELDER, EPDK., https://www.akillisebekelerturkiye.org/, (Haziran 2020).

[2] Deloitte, "Deloitte Türkiye Yayınları, Ak1llı Sayaç Sistemleri: Avrupa uygulamaları analizi ve Türkiye uygulamaları üzerine düşünceler,", https://www2.deloitte.com/content/dam/Deloitte/ tr/Documents/energy-resources/ak1lli-sayacsistemleri.pdf., (Haziran 2020).

[3] Dileep, G. (2020). A survey on smart grid technologies and applications. Renewable Energy, 146, 2589-2625.

[4] Bayindir, R., Colak, I., Fulli, G., \& Demirtas, K. (2016). Smart grid technologies and applications. Renewable and Sustainable Energy Reviews, 66, 499-516.

[5] Alahakoon, D., \& Yu, X. (2015). Smart electricity meter data intelligence for future energy systems: A survey. IEEE Transactions on Industrial Informatics, 12(1), 425-436.

[6] Bayındır, R., \& Demirtaş, K. (2014). Akıllı Şebekeler: Elektronik Sayaç Uygulamaları. Politeknik Dergisi, 17(2), 75-82.

[7] Sun, Q., Li, H., Ma, Z., Wang, C., Campillo, J., Zhang, Q., ... \& Guo, J. (2015). A comprehensive review of smart energy meters in intelligent energy networks. IEEE Internet of Things Journal, 3(4), 464-479.

[8] Öztemür, M., \& Soysal, B. (2013). Ak1llı Şebekeler Yolunda Akıllı Sayaçlar. Akıllı Şebekeler Sempozyumu.

[9] Dağıtım Şirketlerince Kurulacak Osos Kapsamına Dahil Edilecek Sayaçların, Haberleşme Donanımının ve İlave Teçhizat ve Altyapının Ortak Asgari Teknik Özellikleri, https://www.epdk.org.tr/, (Haziran 2020).

[10] Colak, I., Bayindir, R., Fulli, G., Tekin, I., Demirtas, K., \& Covrig, C. F. (2014). Smart grid opportunities and applications in Turkey. Renewable and Sustainable Energy Reviews, 33, 344-352.

[11] Kocaman, B. Teknik Olmayan Enerji Kayıplarının Azaltılmasında PLC Sayaçlarının Önemi. Bitlis Eren Üniversitesi Fen Bilimleri Dergisi, 7(2), 220-230.

[12] Galli, S., \& Lys, T. (2015). Next generation narrowband (under $500 \mathrm{kHz}$ ) power line communications (PLC) standards. China Communications, 12(3), 1-8.

[13] Usta, O., Sonsuz, K., \& Eksi, S. (2008). Akıllı Sayaç Okunma Sistemleri için Alternatif İletişim Ağlarının Değerlendirilmesi, 13. Ulusal ElektrikElektronik-Bilgisayar Kongresi, Ankara.

[14] Khalifa, T., Naik, K., \& Nayak, A. (2010). A survey of communication protocols for automatic meter reading applications. IEEE communications surveys \& tutorials, 13(2), 168-182.

[15] Carratù, M., Ferro, M., Paciello, V., Pietrosanto, A., \& Sommella, P. (2017). Performance analysis of wm-bus networks for smart metering. IEEE Sensors Journal, 17(23), 7849-7856.

[16] LUNA Akıllı Sayaçlar, https://www.lunatr.com/, 
(Haziran 2020).

[17] Abate, F., Carratù, M., Liguori, C., \& Paciello, V. (2019). A low cost smart power meter for IoT. Measurement, 136, 59-66.

[18] Al-Turjman, F., \& Abujubbeh, M. (2019). IoTenabled smart grid via SM: An overview. Future Generation Computer Systems, 96, 579-590.

[19] Implementation of a Single-Phase Electronic Watt-Hour Meter Using the MSP430F6736 (A)., http://www.ti.com/lit/an/slaa517e/slaa517e.pdf.,
(Haziran 2020)

[20] Barai, G. R., Krishnan, S., \& Venkatesh, B. (2015, October). Smart metering and functionalities of smart meters in smart grid-a review. In 2015 IEEE Electrical Power and Energy Conference (EPEC) (pp. 138-145). IEEE.

[21] ESP8266 Series Development Boards, https://www.espressif.com/en/products/hardware /development-boards, (Haziran 2020). 